\title{
A História da matemática e os conhecimentos prévios dos professores como subsídios para o planejamento de um curso sobre geometria esférica e hiperbólica
}

\author{
A History of mathematics and the previous knowledge of teachers as \\ grants for planning a course on geometry ball and hyperbolic
}

Wanderley Pivatto Brum ${ }^{1}$

\section{Resumo}

O objetivo desta pesquisa foi estudar como a evolução histórica da Matemática, tendo como pano de fundo a evolução da geometria, pode auxiliar na formação continuada do professor de Matemática. Para tanto, a sugestão é para um planejamento de curso sobre geometria esférica e hiperbólica estruturado a partir de pressupostos teóricos da aprendizagem significativa, direcionado principalmente a professores de Matemática que atuam no ensino médio. O planejamento do curso foi estruturado: em dados sobre a história da geometria, buscando evidenciar como os conceitos elementares de geometria esférica e hiperbólica desenvolveram-se historicamente; nos conhecimentos prévios mais comuns encontrados na literatura, incluindo um breve esboço de noções identificadas em uma amostra de professores de Matemática de ensino médio e em sugestões de leituras de resultados de pesquisas recentes sobre os processos de ensino e aprendizagem de Matemática. Pretende-se fornecer aos professores elementos de reflexão que Ihe proporcionem mudança de postura, através do questionamento da visão da Geometria, enquanto processo de construção e sobre sua própria prática de ensino. A metodologia sugerida privilegia o trabalho coletivo, com a realização de debates e sínteses. As atividades mencionadas são acompanhadas de justificativas sobre a escolha do tema e objetivos.

Palavras-Chave: História da matemática; Aprendizagem significativa; Ensino de Geometria; Planejamento.

\section{Abstract}

The aim of this research was to study how the historical development of mathematics, with the backdrop of the evolution of geometry, can assist in the continuing education of mathematics' teachers. Therefore, the suggestion is for a course plan on spherical geometry and Hyperbolic structured from theoretical meaningful learning, mainly directed to mathematics' teachers who work in high school. The planning of the course was structured: the data on the history of geometry, seeking to evidence how the basic concepts of spherical geometry and hyperbolic developed historically, previous knowledge commonly encountered in the literature, including a brief outline of concepts identified in a sample of mathematics' teachers in high school and reading suggestions of recent research findings about the processes of teaching and learning Mathematics. It is intended to provide teachers reflection elements that afford them change in posture, through questioning the view of geometry, while a construction process and on their own teaching practice. The methodology proposed considers the collective work, with debates and summaries. The activities mentioned are accompanied by justifications for the choice of topic and objectives.

Keywords: History of mathematics; Meaningful learning; Teaching Geometry; Planning.

\footnotetext{
${ }^{1}$ Secretaria de Educação de Santa Catarina, Brasil - SED/SC
} 


\title{
Introdução
}

Pesquisas realizadas em vários países nas últimas décadas têm mostrado a importância de se considerar no ensino os chamados "conhecimentos prévios" que os estudantes trazem para sala de aula. Inúmeros foram os trabalhos desenvolvidos procurando compreender como a estrutura cognitiva de estudantes e professores encontram-se organizadas em diversas áreas do conhecimento, buscando analisar sua influência na aquisição de conceitos.

Esta extensa literatura indica que:

\begin{abstract}
as crianças realizam representações do mundo que o rodeiam, consoante a sua própria maneira de ver o mundo e de ver a si próprio. Os conhecimentos prévios devem ser encarados como construções pessoais, que o professor tem o dever de procurar conhecer, compreender, e valorizar para decidir o que fazer e como fazer o seu ensino, ao longo do estudo de um tópico. Estes são construídos pelos estudantes a partir do nascimento e o acompanham também em sala de aula, onde os conceitos científicos são inseridos sistematicamente no processo de ensino e aprendizagem (OLIVEIRA, p. 67, 2005).
\end{abstract}

Tais resultados contribuíram para questionar a postura tradicional de ensino, na qual o indivíduo é agente passivo nos processos de aprendizagem. Se apoiando em Mortimer (2000), o ensino efetivo em sala de aula depende também de um elemento facilitador representado pelo professor. Neste caso o professor propicia aos estudantes situações sobre o conteúdo que possam utilizar seus conhecimentos prévios.

O mesmo autor afirma que, o professor pode sugerir uma situação problema relacionada com a realidade dos estudantes, com o intuito de fazer com que busquem em sua estrutura cognitiva, respostas para tal problema. Este fato permite um maior incentivo na caminhada conjunta entre teoria e prática e, ao mesmo tempo, entre o real e o imaginário, em detrimento ao estilo de ensino unilateral, onde somente o professor transmite o conhecimento aos estudantes, considerado o detentor do saber.

Ao mesmo tempo, levantaram-se sérias indagações: como encarar o processo educativo a partir disso? O que significa realmente ensinar e aprender? Como ensinar conceitos científicos de modo que os estudantes realmente aprendam? Quais garantias é possível obter após anos de ensino formal quando nossa primeira resposta a um certo problema será baseada em explicações cientificamente aceitas? Seremos capazes de modificar nossos conhecimentos prévios? Quais são os papeis dos estudantes e do professor nesse processo?

Neste trabalho, o foco é a geometria esférica e hiperbólica, uma vez que possuem importantes aplicações práticas na navegação, na astronomia, no comportamento da luz e na compreensão de objetos encontrado na natureza, como bancos, trompetes, ondas, etc.

Enquanto a linguagem cotidiana é muitas vezes responsável pela disseminação de explicações não científicas, cita Carrascosa, Perez e Valdés (2005), onde o estudante apresenta significado para imagens, símbolos, modelos e representações geométricas, permitindo uma compreensão do mundo que o cerca, a prática de ensino formal de Matemática em todos os níveis privilegia a memorização de fórmulas e técnicas de 
resolução de problemas, ou seja, um ensino centrado no livro didático e na exposição do professor.

Por outro lado, a visão linear, e muitas vezes alienada, da produção do conhecimento que permeia este tipo de ensino, reforça a ideia de que matemática é para poucos gênios privilegiados que acertam sempre os problemas propostos. Ao largo, não contempla o aspecto de construção, os erros, os conhecimentos superados, e a própria compreensão de modelos. É a história da Matemática para gênios. Esta distorção limita a compreensão do mundo que nos cerca, das possíveis representações e singularidades, o que leva o indivíduo a viver em um mundo utópico e ideal (SILVA, 2006).

A proposta aqui apresentada privilegia a formação do professor, entendendo que esta se constitui na base para uma reformulação dos processos de ensino, e provavelmente, no de aprendizagem. A proposta é subsidiar a ação docente, fornecendo elementos para a construção de atividades de ensino sobre conceitos elementares de geometria esférica e hiperbólica para estudantes de ensino médio baseado em pressupostos da Teoria da Aprendizagem Significativa ${ }^{2}$. Apoio em Mendes (2001) quando afirma que, através do conhecimento geométrico não euclidiano, o estudante é capaz de pensar e compreender as leis matemáticas a partir de certas propriedades e artifícios usados hoje que foram difíceis de descobrir em períodos anteriores ao que vivemos.

O motivo pela escolha do tema, dentre os inúmeros problemas pelos quais a Matemática tem passado nos últimos anos, um dos que se tem destacado, basicamente, na área da Educação Matemática é o seguinte: como melhorar o ensino da Matemática. Isso porque muitas dificuldades são enfrentadas pelos professores e estudantes desta ciência, em qualquer nível de ensino. Essa questão pressupõe que o aperfeiçoamento da prática pedagógica dos professores pode contribuir para solucionar os desafios surgidos durante a produção do conhecimento matemático.

Entre as muitas dificuldades encontradas pelos professores, a relutância em aceitar e utilizar inovações se destaca, e:

Tal dificuldade surge no fato de que se deve estabelecer uma nova visão de aprendizagem em sala de aula e os professores têm de participar de mudanças fundamentais de opinião necessárias para que esta nova proposta torne-se realidade Outra dificuldade é determinada pela concepção que os professores têm sobre ciência e seu ensino, que fazem com que eles as considerem basicamente como processos de exploração e as dinâmicas em sala de aula dirigidas a controlar o comportamento do estudante Fato é que, nossos professores não estão acostumados a usar a informação dos estudantes para revisar a toma de decisões instrucionais (DUSCHL, p, 134, 1995).

\footnotetext{
${ }^{2}$ A metodologia para subsidiar a ação docente frente ao tema geometria esférica e hiperbólica a partir de pressupostos da Teoria da Aprendizagem Significativa, busca contemplar simultaneamente os conhecimentos prévios, o uso de organizadores prévios, os tipos e as formas de aprendizagem significativa e os processos de desenvolvimento de apropriação do conhecimento por meio da reconciliação integrativa e diferenciação progressiva.
} 
Pérez (1998) evidencia que a grande maioria de professores de Matemática têm toda uma série de ideias, comportamentos e atitudes em torno dos problemas de ensino e aprendizagem que podem constituir obstáculos para uma atividade docente inovadora, na medida em que se trata de conhecimentos prévios, aceitos acriticamente como parte de uma docência de "senso comum". O autor sintetiza uma proposta baseada na noção de aprendizagem através da construção de conhecimentos com as características de uma investigação e pautado na necessidade de modificar o pensamento do professor.

A problemática que se apresenta para este trabalho é fruto da preocupação com a formação do docente de Matemática que atua no ensino médio. A partir do tema geometria esférica e hiperbólica, foi desenvolvido um plano de curso utilizando como subsídios: 1) os conhecimentos prévios dos professores, 2) a história da Matemática (em especial da Geometria) e 3) resultados de pesquisas recentes sobre os processos de ensino e aprendizagem. Mais do que discutir situações envolvendo geometria esférica e hiperbólica, este curso pretende utilizar a história da Matemática como pano de fundo de discussões que envolvam a formação do docente, encarada de forma ampla. A proposta visa fornecer elementos de reflexão que proporcionem mudanças de postura na ação docente.

\section{Os pressupostos da Teoria da Aprendizagem Significativa}

A teoria da aprendizagem significativa foi formulada inicialmente pelo psicólogo norte americano David Paul Ausubel. As ideias de Ausubel, cujas formulações iniciais são dos anos 60, se encontram entre as primeiras propostas psicoeducativas em sua obra "Psicologia Educacional", recebendo colaborações em 1980 de Joseph Donald Novak e Helen Hanesian, acerca de fatores sociais, cognitivos e afetivos na aprendizagem.

[...] é essencial levar-se em consideração as complexidades provenientes da situação de classe de aula, estes por sua vez, incluem a presença de muitos alunos de motivação, prontidão e aptidões desiguais; as dificuldades de comunicação entre professor e aluno; as características particulares de cada disciplina que esta sendo ensinada; e as características das idades dos alunos (AUSUBEL; NOVAK; HANESIAN, 1980, p. 5)

Para os autores, basicamente, a ideia central de aprendizagem significativa é uma reorganização clara da estrutura cognitiva, isto é, um processo pelo qual uma nova informação se relaciona com um aspecto relevante na estrutura do conhecimento do estudante. A aprendizagem significativa é uma tentativa de fornecer sentido ou estabelecer relações de modo não arbitrário e substancial (não ao pé da letra) entre os novos conhecimentos e os conceitos que existem no estudante. Em contraponto à aprendizagem significativa, surge a aprendizagem mecânica que para Ausubel, Novak e Hanesian (1980) é o tipo de aprendizagem, diferentemente do processo significativo, ocorrendo quando o estudante é apresentado a um novo conhecimento, e este, por motivos variados, não o relaciona com algum conceito que já exista em sua mente, simplesmente, incorpora - se na sua estrutura cognitiva de maneira arbitrária e não substantiva. 
A aprendizagem (significativa ou mecânica) ocorre por meio de recepção, enfatizado por Moreira (2010) como aquela em que todo o conteúdo vai ser aprendido é apresentada ao estudante na forma final ou por descoberta onde os conceitos não são fornecidos, mas deve ser "descoberto" pelo estudante antes que possa ser incorporado significativamente na sua estrutura cognitiva. No entanto, a aprendizagem por descoberta, não é necessariamente significativa, nem aprendizagem por recepção é obrigatoriamente mecânica, mas se apresentam como um continuum. Para o autor, uma posição mais defensável é de que tanto a aprendizagem receptiva ou por descoberta podem ser mecânicas ou significativas dependendo das condições que ocorre a aprendizagem.

Em ambos os casos (recepção ou descoberta) a aprendizagem significativa ocorre quando há um processo de interação no qual os conceitos mais relevantes e inclusivos (subsunçores) integram com o novo material a ser aprendido. A aprendizagem significativa é caracterizada por uma interação entre os aspectos específicos e relevantes da estrutura cognitiva e as novas informações, por meio das quais essas adquirem significado e são integradas a uma estrutura hierárquica altamente organizada de subsunçores de maneira não arbitrária e não literal.

A aprendizagem significativa deve preponderar em relação a aprendizagem de associações arbitrárias, organizacionalmente isoladas, mecânica. Para isso, algumas condições são apontadas por Ausubel, Novak e Hanesian (1980):

A existência prévia de conceitos subsunçores, compreendido pelos autores como um conceito já existente na estrutura cognitiva, capaz de servir de ancoradouro a uma nova informação, de modo que esta adquira significado para o estudante;

O estudante precisa ter uma disposição para aprender: se o indivíduo quiser memorizar o conteúdo arbitrária e literalmente, então a aprendizagem será mecânica. A aprendizagem significativa pressupõe que o estudante manifeste uma disposição para a aprendizagem, ou seja, disposição para se relacionar de forma não arbitrária e substantiva ao novo conhecimento;

O conteúdo escolar a ser aprendido tem que ser potencialmente significativo, ou seja, deve estar relacionado à estrutura cognitiva do estudante, portanto, devem estar disponíveis em sua estrutura cognitiva subsunçores adequados.

A partir destas condições, Pozo (1998) cita que é preciso entender que existe uma modificação no conhecimento, balizado pela manifestação de interesse em aprender por parte do estudante e o material deverá ser potencialmente significativo. A percepção de uma aprendizagem significativa se consolida por meio de um processo que é considerado dinâmico e não unilateral, no qual os estudantes carregados de interconexões mentais e saberes se tornam peça fundamental nesse movimento de construção do conhecimento, contudo, se o estudante deseja simplesmente memorizar, o processo de aprendizagem será mecânico e sem significado.

No curso da aprendizagem significativa, Moreira (2010) enfatiza que os conceitos interagem com os novos conteúdos, servindo de base para a atribuição de novos significados que também se modificam. Essa mudança progressiva vai tornando um subsunçor mais elaborado, mais diferenciado, capaz de servir de âncora para a aquisição de novos conhecimentos, processo este que Ausubel chama de diferenciação progressiva. 
Outro processo que ocorre no encadeamento da aprendizagem significativa é o que Moreira (2010) denomina de estabelecimento de relações entre ideias, que podem ser conceitos, proposições que já se encontram na estrutura cognitiva. A existência de conceitos estáveis e com certo grau de diferenciação são relacionados com outros conceitos, passando a adquirir novos significados levando a uma reorganização da estrutura cognitiva. Essa reorganização de conceitos é conhecida por reconciliação integrativa.

A busca de indícios para a ocorrência de uma aprendizagem significativa não é uma tarefa simples. Verificar se uma aprendizagem ocorreu, segundo Ausubel, Novak e Hanesian (1980), simplesmente perguntando ao estudante os atributos de um conceito ou proposição é arriscado, haja vista a possibilidade da utilização de respostas mecanicamente memorizadas. Os autores entendem que é necessária uma compreensão no domínio dos significados que se apresentam de forma clara, precisa, diferenciados e transferíveis.

Uma sugestão apresentada por Ausubel e defendida por Moreira e Masini (2001), com objetivo de evitar uma simulação da aprendizagem significativa, é utilizar situações que sejam novas e não familiares, exigindo máxima transformação do conhecimento existente. Há diversas alternativas para verificação da ocorrência da aprendizagem significativa, como tarefas de aprendizagem sequencialmente vinculadas, servindo de apoio a etapas posteriores da atividade, a resolução de problemas bem como a utilização de mapas conceituais.

Na busca de indícios de uma possível aprendizagem significativa, um importante aspecto é partir dos conhecimentos que os estudantes trazem para dentro da sala de aula. "Se tivéssemos que reduzir toda a psicologia educacional a um único princípio diríamos que o fator singular mais importante que influencia a aprendizagem é aquilo que o aprendiz já sabe, descubra isso e baseie-se nisso seus ensinamentos" (AUSUBEL; NOVAK; HANESIAN, 1980, p. 137). Nesta vertente, o projeto educativo do professor deve está direcionado para o desenvolvimento cognitivo dos estudantes, priorizando os conhecimentos prévios, reconhecido que raramente vem marcado por estudos avançados, servindo assim de ancoragem para as novas ideias e conceitos, constituindo a base fundamental para do processo de aprendizagem.

Durante o processo da aprendizagem significativa, a nova informação não estabelece uma espécie de elo com os elementos preexistentes da estrutura cognitiva, ao contrário, esses elos só ocorrem na aprendizagem automática. Na aprendizagem significativa, há uma mudança tanto na nova informação como no subsunçores com a qual o novo conhecimento estabelece relação, sendo que o resultado dessa interação é a assimilação de significados.

Segundo Moreira e Masini (2001) a assimilação é um processo que ocorre quando um conceito ou proposição potencialmente significativa é assimilado sob um ideia ou conceito mais inclusivo, já existente na estrutura cognitiva. A assimilação é compreendida como um relacionamento entre os aspectos relevantes, preexistentes da estrutura cognitiva, e tanto a nova informação como a preexistente são modificadas no processo. A teoria ausubeliana apresenta três formas de aprendizagem significativa, segundo a teoria da assimilação: a subordinada, superordenada e a combinatória. 


\section{Aprendizagem subordinada}

Segundo Ausubel (2003), a maior incidência de aprendizagem significativa é do tipo subordinada, ou seja, a nova ideia aprendida se encontra hierarquicamente subordinada a ideia preexistente. Coll, Marchesi e Palácios (2007) comentam que a estrutura cognitiva do sujeito responde a uma organização hierárquica na qual os conceitos se conectam entre si mediante relações de subordinação, dos mais gerais aos mais específicos.

\section{Aprendizagem superordenada}

Nesta forma de aprendizagem significativa o novo conceito é mais geral e inclusivo que os conceitos subsunçores. Ocorre quando um conceito ou proposição mais geral do que algumas ideias já estabelecidas na estrutura cognitiva do estudante, é adquirido e passa a ser assimilado. Para Ausubel, Novak e Hanesian (1980) a nova aprendizagem será superordenada quando se aprende uma nova proposição inclusiva que condicionará o surgimento de várias ideias, ocorrendo no curso do raciocínio ou quando o material apresentando é organizado indutivamente ou envolve a síntese de ideias compostas.

\section{Aprendizagem combinatória}

A aprendizagem de novas proposições que não apresentam relação subordinada nem superordenada com ideias relevantes já adquiridas anteriormente na estrutura cognitiva do estudante é denominada aprendizagem combinatória. Conforme Pozo (1998) na aprendizagem significativa combinatória, a ideia nova e as ideias já estabelecidas não estão relacionadas hierarquicamente, porém se encontram no mesmo nível, não sendo nem mais específica nem mais inclusiva do que outras ideias. Ao contrário das proposições subordinadas e superordenadas, a combinatória não é relacionável a nenhuma ideia particular da estrutura cognitiva.

\section{Os conhecimentos prévios mais comuns sobre o tema}

O levantamento dos conhecimentos prévios realizado a partir de diversas pesquisas ( $p$. ex. Brum, 2013; Andrade, 2011; Leivas, 2012; Prestes, 2006; Cabariti, 2004; Cavichiolo, 2011; Melo, 2013) revelou determinados padrões de pensamento que se repetem e podem, de certa forma, ser generalizados.

- É possível a partir de qualquer ponto da Terra, retornar por meio de uma reta.

- A geometria esférica não difere muito da geometria euclidiana.

- Para ir de Florianópolis a Fernando de Noronha, o caminho será uma reta.

- A menor distância entre dois pontos na esfera é uma reta.

- Um objeto que se aproxima da geometria hiperbólica seria uma sela de cavalo.

- O avião anda em linha reta, pode bater, sofrer turbulência, mas chegará ao seu destino.

- Acredito que não exista o fim do mundo, até mesmo por que vivemos em uma esfera, porém já ouvi histórias de navios que desapareciam.

- Acredito que existam retas paralelas sobre uma esfera, seriam dois paralelos.

- O transferidor só pode ser usado em superfícies planas. 
- Uma figura com três lados de arcos de circunferências máximas e três vértices seriam os ângulos esféricos.

- A Terra é esférica e o modelo na escola para representa-la é um globo.

- A geometria hiperbólica, embora importante, não tem qualquer aplicação no cotidiano.

\section{A história da Matemática e o ensino de geometria}

Não há consenso no que diz respeito à utilização da História da Matemática no ensino. É possível evidenciar o conteúdo de algumas críticas:

- Há lacunas na formação do professor;

- Os currículos "inchados" não poderiam incluir discussões de questões históricas adequadamente;

- Há uma declarada tendência dos professores optarem pelo ensino de Álgebra e Aritmética, colocando como pano de fundo a Geometria;

- Entretanto, diversos autores, por exemplo, Kallef (2004), Bongiovani (2010), Carvalho (2011), Martos (2012) discutem alguns argumentos que corroboram a utilização da história da Matemática para:

- Proporcionar uma visão mais adequada da história da Matemática, em especial, da geometria enquanto processo de construção;

- Servir como base de elementos de reflexão na definição de temas fundamentais, como reta, superfície e ângulo;

- Revelar obstáculos epistemológicos através da semelhança entre os conhecimentos prévios e conhecimentos relativos a teorias científicas, quando possível;

\section{O curso proposto}

O curso é apresentado em quatro partes: 1) Atividades introdutórias ou de reconhecimento, 2) atividades de conhecimento epistemológico/científico, 3) atividades de reflexão acerca dos referenciais teóricos utilizados sobre a aprendizagem significativa e aprendizagem em Matemática e 4) atividades de síntese das ideias debatidas.

Tal "fragmentação" entretanto, serve apenas para fins didáticos e, absolutamente, constitui-se de blocos estanques. Assim, espera-se que o desenvolvimento do curso dependa das características do grupo, diagnosticada conforme previsto nas "atividades introdutórias ou de reconhecimento".

1) Atividades introdutórias ou de reconhecimento

A realização de atividades introdutórias, visa identificar, dentre outros aspectos, os conhecimentos prévios que os professores possuem sobre geometria esférica e hiperbólica e suas visões sobre a Matemática. A teoria da aprendizagem significativa ao estabelecer o conhecimento prévio do sujeito como referência, explicita claramente que este é elemento básico e determinante na organização do ensino.

Para tanto, sugiro alguns instrumentos que podem ser aplicados:

- Diagnóstico de conhecimentos dos professores sobre o tema (Geometria Esférica e Hiperbólica), a partir da utilização de questões presentes na literatura; 
- Análise do planejamento de ensino utilizado pelos professores. Caso haja consentimento por parte dos professores, esta atividade poderá ser implementada pela comparação de uma aula (ou sequência de aulas) gravada, ministrada por um ou vários participantes para que os conteúdos, a metodologia e demais procedimentos didáticos discutidos e analisados pelo grupo.

\section{2) Atividades de conhecimento epistemológico/científico}

Estas atividades têm como objetivo permitir que o professor participante elabore em uma primeira etapa uma visão geral da construção histórica do tema Geometria Esférica e Hiperbólica e entre em contato com alguns dos conhecimentos prévios mais comuns. Essas atividades se caracterizam como organizadores prévios,uma estratégia desenvolvida por Ausubel (2003), que consiste na utilização de materiais auxiliares, antes do próprio material de aprendizagem, com a finalidade de criar pontos de ancoragem, em nível mais geral do que o material mais detalhado que a precede.

Tais organizadores devem ser utilizados quando o estudante não dispõe em sua estrutura cognitiva, de subsunçores que ancorem novos conhecimentos ou quando for constatado que, os subsunçores identificados não estão suficientemente claros ou encontram-se desorganizados para desempenhar as funções de ancoragem. Os textos utilizados para tal foram extraídos de extensa revisão bibliográfica sobre o tema, iniciando com os primeiros estudos de Geometria não Euclidiana, passando por nomes como: Euclides, Gauss, Bolyai, Beltrami, entre outros e concluindo com os trabalhos de Riemann e Lobachevsky. Os temas são mostrados na sequência apresentada na figura 1.

A etapa seguinte visa permitir o estabelecimento de relações entre as geometrias esférica e hiperbólica estudados. A busca por similaridades e divergências entre as geometrias estudadas, evidencia a necessidade de satisfazer um dos pressupostos da teoria da aprendizagem significativa que é proporcionar o processo de aprendizagem subordinada, onde os conceitos apresentados encontram-se subordinados ao conceitos mais geral, que é Geometria. As atividades mencionadas são acompanhadas de justificativas sobre a escolha do tema e objetivos. A avaliação será baseada:

- Na produção individual dos participantes, que deverá ser continuamente discutida;

- Nas sínteses individuais que deverão ser elaboradas ao final das discussões plenárias de cada atividade;

- No desenvolvimento coletivo, por meio de exposição e sínteses elaboradas.

3) Atividades de reflexão acerca dos referenciais teóricos sobre a aprendizagem e a aprendizagem de Matemática

Nesta etapa do curso, serão discutidos textos que serviram como fundamentação teórica desta pesquisa e outros que contemplam as discussões mais recentes sobre o ensino da Matemática. A partir das discussões sobre a teoria da aprendizagem significativa presentes nos trabalhos de Ausubel (2003), Novak e Gowin (1996), Moreira (2010), Coll, Marchesi e Palácios (2007) que discutem o fato de que a mudança conceitual raramente envolve um completo abandono de uma noção a favor de outra. Culmina-se por adotar 
como base das atividades os pressupostos teóricos de aprendizagem significativa em Ausubel, Novak e Hanesian (1980), conforme é estudado nesse trabalho.

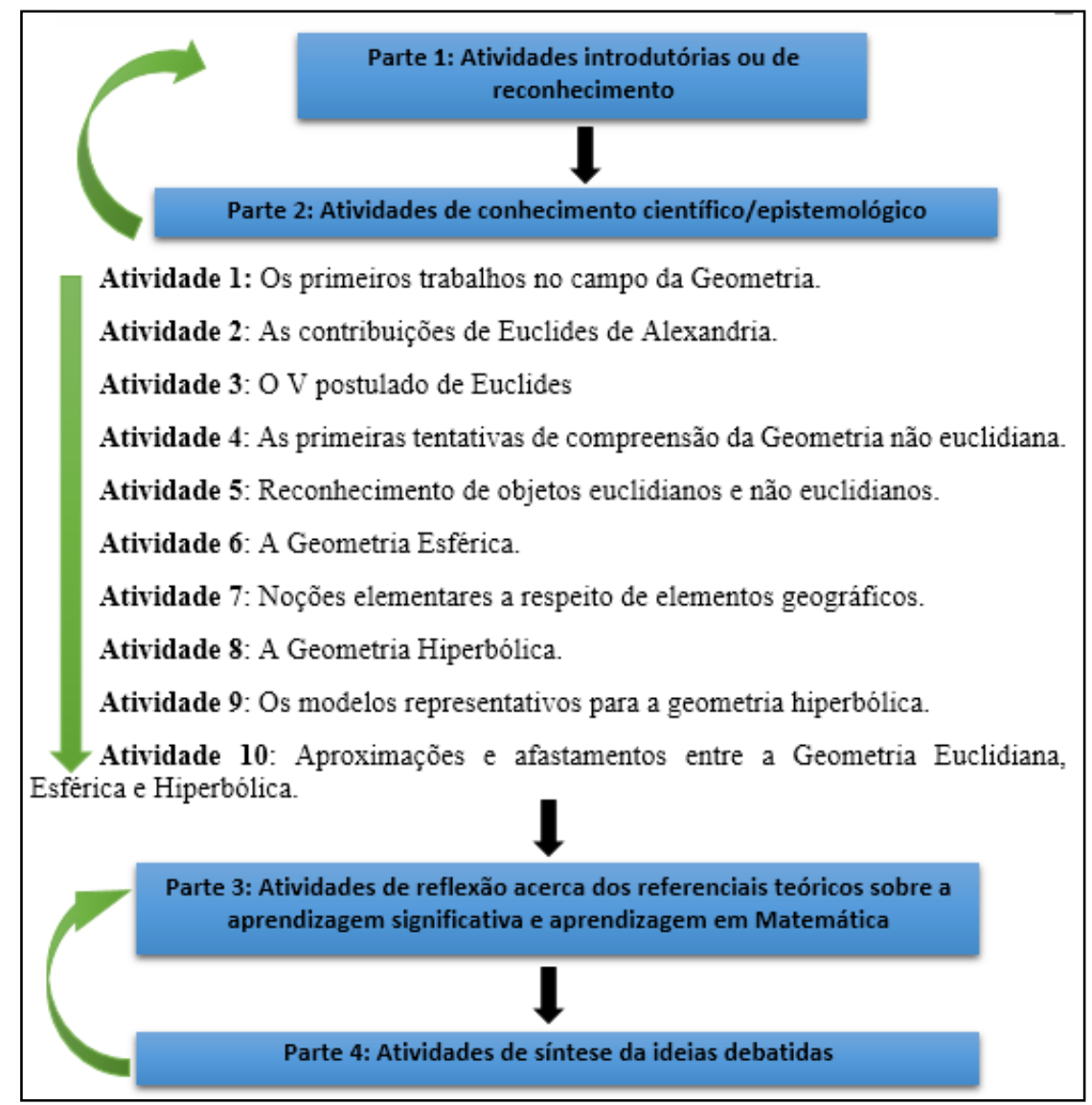

Figura 1: Sequência proposta para o desenvolvimento o curso.

4) Atividades de síntese das ideias debatidas

Nesta parte do curso, será estabelecido ao professor que elabore uma espécie de "retrospectiva" incluindo os assuntos debatidos que ele considerou mais relevantes e possíveis mudanças de atitude sentidas. Mediante essa retomada, o professor deverá reelaborar o planejamento de ensino que entregou por ocasião da realização das atividades introdutórias.

Ausubel, Novak e Hanesian (1980) assinalam a importância de se desenvolverem atividades mais gerais, que permitam generalizações como forma de impedir que a simples reprodução de fatos seja confundida com aprendizagem conceitual. Sugere-se ainda, que levantamentos semelhantes àqueles realizados na parte 1 da proposta (atividades introdutórias) sejam novamente conduzidas. Tais atividades visam proporcionar ao professor uma oportunidade de sintetizar as principais ideias discutidas durante a realização do curso e fornecer elementos de análise, não apenas das possíveis mudanças individuais, como também do processo como um todo, conforme mostra a sequência apresentada na figura 1 . 


\section{Um exemplo de atividade proposta}

Após uma extensa revisão sobre a história da Geometria, foi decidido estruturar as atividades propostas a partir de pressupostos teóricos da Aprendizagem Significativa de Ausubel (2003), conforme figura 2.

- Organizador prévio (Conceitos âncora);

- Conhecimento científico/epistemológico (Conceitos gerais - valorização a aprendizagem superordenada);

- Conhecimento científico/epistemológico (Conceitos inclusivos - valorização a aprendizagem subordinada e combinatória);

- Habilidade cognitiva/reflexão (Valorização a aprendizagem representacional, conceitual e proposicional)

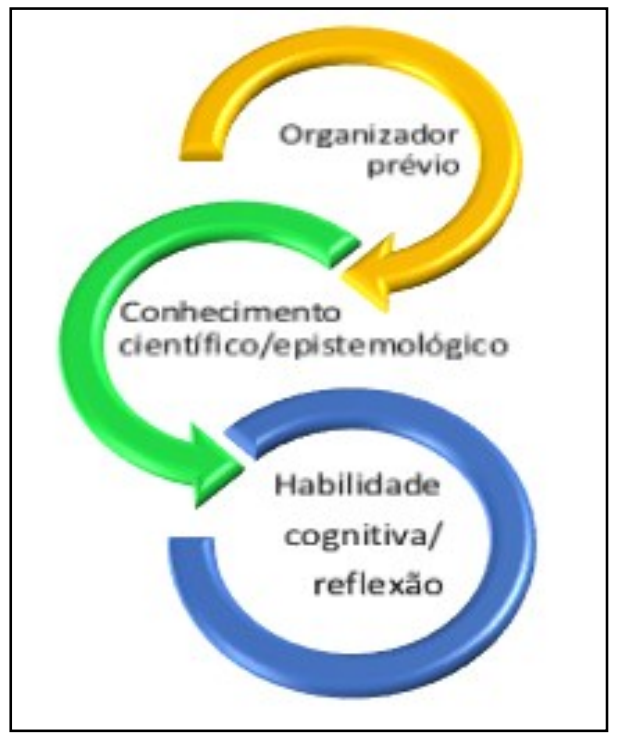

Figura 2: pressupostos teóricos de Ausubel (2003).

A atividade descrita no quadro 1, procura esclarecer a proposta do curso.

Quadro 1: Planejamento da atividade 1.

\begin{tabular}{|l|l|}
\hline Pressupostos teóricos & Descrição das etapas de trabalho \\
\hline Atividade 1 & Os primeiros trabalhos no campo da Geometria. \\
\hline Organizador prévio & $\begin{array}{l}\text { Um panorama da história da Geometria contada pelas civilizações } \\
\text { antigas. }\end{array}$ \\
\hline $\begin{array}{l}\text { Conhecimento } \\
\text { científico/epistemológico }\end{array}$ & $\begin{array}{l}\text { Os egípcios e a agrimensura: o uso do método indutivo. } \\
\text { Os gregos e os teoremas: o uso do método dedutivo e axiomático. }\end{array}$ \\
\hline $\begin{array}{l}\text { Habilidade } \\
\text { cognitiva/reflexão }\end{array}$ & Análise, argumentação e síntese das ideias principais \\
\hline $\begin{array}{l}\text { Sequência } \\
\text { instrucional } \\
\text { (conversação avaliativa) }\end{array}$ & $\begin{array}{l}\text { 1. Leitura individual do material apresentado. } \\
\text { 2. Discussão das questões em pequenos grupos. } \\
\text { 3. Apresentação plenária das ideias debatidas. } \\
\text { 4. infose das elaborações, facilitando o feedback que servirá para avaliar } \\
\text { 5. Aplicação das novas ideias debatidas (reflexão sobre a prática } \\
\text { pedagógica). }\end{array}$ \\
\hline
\end{tabular}


Atividade 1: Os primeiros trabalhos no campo da Geometria.

Esta atividade propõe uma discussão acerca das ideias dos primeiros trabalhos envolvendo conceitos elementares de geometria. Pretende-se fornecer subsídios para que o professor compreenda a evolução da geometria, além de discutir a existência de conhecimentos prévios relatados na literatura, semelhantes a algumas noções presentes na geometria egípcia e grega.

A proposta da aplicação das novas ideias, mais explícita na questão 6, visa uma reflexão sobre as implicações pedagógicas dos conteúdos desenvolvidos na atividade.

Textos de apoio (fundamentação histórica)

Os textos propostos para apoiar esta atividade são extraídos da revisão bibliográfica especialmente elaborada para subsidiar as atividades do curso. Neste caso especifico, os temas escolhidos foram: Sobre o Despertar do Pensamento Geométricoe O Livro de Ouro da História do Mundo: Da Pré-História à Idade Contemporânea, que procuram explanar as principais ideias presentes sobre a história da geometria.

Questões

1. Explique como, no Antigo Egito, há mais de 4.500 anos, a geometria já era usada nas situações de medição de terras.

2. Dentro da história da Geometria, existe a possibilidade de se cogitar algum outro trabalho realizado por povos antigos envolvendo noções geométricas? Explique.

3. O filósofo grego Teles mencionou a geometria como sendo uma das pragas para os jovens. Da mesma forma, Isocrates disse que a maioria das pessoas achava o estudo da geometria ocioso, "...uma vez que não tem utilidade em compromissos públicos ou privados; a maior parte das vezes ficam esquecidos, justamente por não serem necessários na nossa vida diária e ativa, ..., está completamente fora das necessidades de todos os dias.".Você concorda com o pensamento desses filósofos? Comente.

4. Será na Grécia do séc. 7 a.C. que a geometria se estabelece como ciência dedutiva. Por que a geometria grega é a geometria da régua e do compasso? Os gregos herdam toda a experimentação, intuição e empirismo de qual povo, estipulando neles leis e regras acerca do espaço?

Textos de apoio (sobre conhecimentos prévios)

Estes textos buscam, como citado anteriormente, permitir que o professor entre em contato com os conhecimentos prévios mais comuns sobre o tema.

Alguns conhecimentos prévios sobre a história da geometria, encontradas na literatura, são semelhantes a noções presentes ao largo da linha do tempo referente a evolução da geometria. Almouloud (2004) e Kalleff (2004), apresentaram os conhecimentos prévios sobre história da geometria de um grupo de estudantes que cursavam diferentes níveis de curso no ensino básico. 
No caso da história da geometria, para muitos estudantes as primeiras representações geométricas são associadas a arte rupestre. Algumas justificativas apresentadas pelos estudantes:

- Porque lá encontram-se os primeiros desenhos.

- É possível que os primeiros desenhos geométricos estejam ainda registrados nas paredes de cavernas.

- Existem muitos desenhos, como linhas paralelas, pontos e círculos encontrados em desenhos dos povos das cavernas.

Os autores revelam que, entre estudantes que tinham concluído o ensino médio, o nível de respostas corretas aumentou em relação aqueles que ainda não o tinham feito. Entretanto, o ensino formal não foi capaz de modificar as noções alternativas.

No estudo realizado por Mendiola (2002), para 61,43\% da amostra pesquisada existe a necessidade de considerar a arte rupestre como um dos primeiros movimentos para a história da geometria (figura 3).
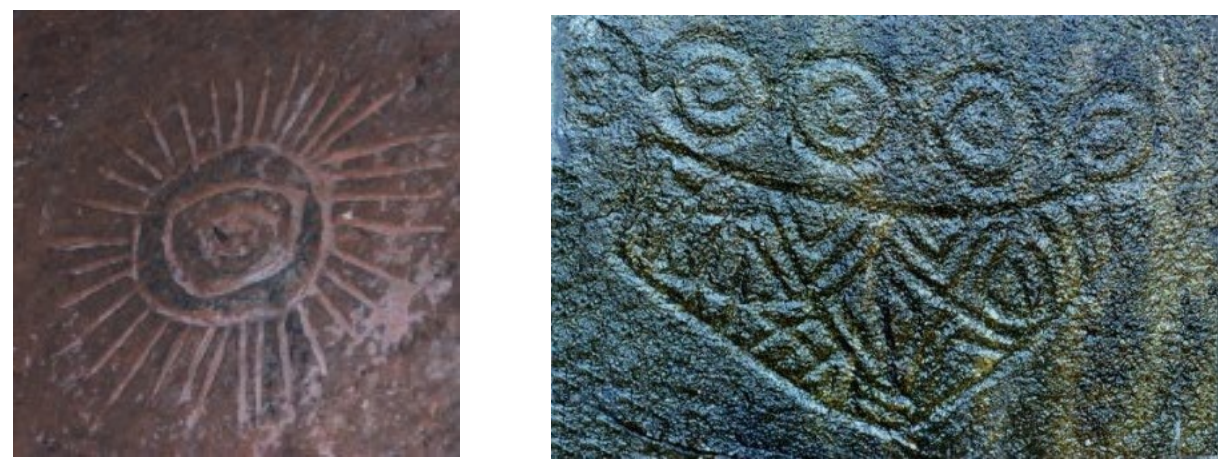

Figura 3: Representação dos conhecimentos prévios expressada pela maioria dos estudantes entrevistados: arte rupestre como primeiros ensaios para a história da geometria. (Adaptado de Mendiola, 2002).

Questões

1. Você acredita que um indivíduo que sustente algumas noções, como as apresentadas anteriormente, valoriza mais a história da geometria nas cavernas, em detrimento daquela que é comentada na escola? Justifique.

2. De que maneira as informações discutidas até aqui podem ajudá-lo em sua ação docente?

\section{Considerações finais}

O curso proposto neste trabalho tentou incorporar os resultados de pesquisas recentes sobre os processos de ensino e aprendizagem em Matemática, sobre os conhecimentos prévios e sobre a utilização da história da Geometria no ensino de Matemática, buscando sintetizar tais elementos com a finalidade de contribuir na formação (inicial e/ou continuada) do professor de Matemática.

É possível afirmar que a história da Matemática ocupa um lugar de destaque nesta proposta, constituindo o pano de fundo sobre o qual as discussões deverão ser realizadas. Entendo que esse plano de curso proposto poderá ser discutido de forma mais profunda no 
momento em que for aplicado em situações concretas, fornecendo o feedback necessário para sua avaliação e gerando importantes elementos para o redirecionamento dos objetivos, conteúdos e estratégias agora sugeridos.

Entendo também que os resultados desta pesquisa, depois de analisados num contexto real, poderão ser estendidos para outras situações de ensino, por exemplo utilizando a abordagem aqui proposta para o ensino de outros tópicos da Matemática.

De maneira mais ampla, pode-se trabalhar com esta abordagem conteúdos de Geometria em geral, uma vez que os pressupostos teóricos aqui empregados, tanto em relação a questões de ensino e aprendizagem quando àquelas relativas à inserção da história da Matemática no ensino, podem ser perfeitamente utilizados em situações de ensino e aprendizagem das diversas áreas da matemática.

\section{Referências}

ALMOULOUD, S. A. A geometria no ensino fundamental: reflexões sobre uma experiência de formação envolvendo professores e alunos. Revista Brasileira de Educação, São Paulo, n. 27, p. 94 108, Set/Out/Nov /Dez 2004.

ANDRADE, M.L.T. Geometria esférica: uma sequência didática para a aprendizagem de conceitos elementares no ensino básico, 2011, 120f. Dissertação (Mestrado em Educação Matemática) Pontifícia Universidade Católica de São Paulo.

AUSUBEL, D.P.Aquisição e retenção de conhecimentos: Uma perspectiva cognitiva Editora Plátano, 2003.

AUSUBEL, D.P; NOVAK, J.D.; HANESIAN, H. Psicologia Educacional. Rio de Janeiro: Interamericana, 1980.

BONGIOVANI, V. De Euclides às geometrias não euclidianas. Revista Iberoamericana de Educación Matemática. São Paulo, v.1, n. 22, p. 37-51, 2010.

BRUM, W.P. Abordagem de conceitos elementares de geometria esférica e hiperbólica no ensino médio usando uma sequência didática, 2013, 187f. Dissertação (Mestrado em Ensino de Ciências Naturais e Matemática) - Universidade Regional de Blumenau.

CARRASCOSA, J., PEREZ, D. e Valdés, P. Como ativar a aprendizagem significativa conceitos e teorias? Santiago: OREALC / UNESCO, 2005.

CARVALHO, Maria Aparecida da Silva de; CARVALHO, Ana Márcia Fernandes Tucci de Carvalho. O ensino de geometria não euclidiana na educação básica. In: XIII Conferência Interamericana de Educação Matemática, 2011, Recife.

CAVICHIOLO, C.V. Geometrias não euclidianas na formação inicial do professor de matemática: o que dizem os formadores. Dissertação (Mestrado em Educação) - Universidade Federal do Paraná.

COLL, C.; MARCHESI, A.; PALACIOS, J. Desenvolvimento psicológico e educação: psicologia da educação escolar. $2^{\mathrm{a}}$ ed. Porto Alegre: Artmed, 2007.

DUSCHL, R.A. Más alládelconocimiento: los desafios epistemológicos y sociales de laenseñanza mediante el cambio conceptual.Enseñanza de lasCiencias, v.13, n.1, p. 3-14, 1995.

FERREIRA, L. Construção de atividades parar o ensino de geometria hiperbólica. Anais do Encontro de Produção Científica e Tecnológica. São Paulo, 2011. 
KALEFF, A.M. Desenvolvimento de Atividades Introdutórias ao Estudo das Geometrias não Euclidianas: Atividades Interdisciplinares para Sala de Aula e Museus Interativos. In: Congresso Brasileiro de Extensão Universitária, n. 2, 2004. Belo Horizonte.

LEIVAS, J.C.P. Educação geométrica: reflexões sobre ensino e aprendizagem em geometria. Revista SBEM-RS, Porto Alegre, n. 13, v.1, p. 9-16, 2012.

MARTOS, Z.G. Geometrias não euclidianas: uma proposta metodológica para o ensino de Geometria no Ensino Fundamental. Rio Claro, 2002. 143f. Dissertação (Mestrado em Educação Matemática) Instituto de Geociências e Ciências exatas, Universidade Estadual Paulista.

MELO, E.M. A topologia no ensino médio: uma proposta de um novo olhar com mapas conceituais. Anais do XI Encontro nacional de Educação Matemática: educação matemática retrospectivas e perspectivas. Curitiba, 2013.

MENDES, I. A. O uso da história da matemática: reflexões teóricas e experiências. Belém:EDUEPA, 2001.

MENDIOLA G. F. Arte rupestre: epistemología, estética y geometría. Sus interrelaciones con la simetría de la cultura. Ensayo de explicación sobre algunas ideas centrales de Adolfo Maugard y Beatriz Braniff. En Rupestre/web, http://rupestreweb.tripod.com/mendiola2.html. 2002. Acesso em 20/10/2013.

MOREIRA, M. A. Mapas conceituais e aprendizagem significativa. São Paulo: Centauro, 2010.

MOREIRA, M.A.; MASINI, E. F. S. Aprendizagem significativa: A teoria de David Ausubel. São Paulo: Centauro, 2001.

MORTIMER, E. F. Pressupostos epistemológicos para uma metodologia de ensino de química: mudança conceitual e perfil epistemológico. Química Nova, v. 15, n. 3, p. 242-249, 2000.

NOVAK, J.D.; GOWIN, B. D. Aprender a Aprender. Lisboa: Plátano Edições Técnicas, 1996.

SILVA, A.F.A. Ensino e aprendizagem de Ciências nas séries iniciais: concepções de um grupo de professoras em formação. Dissertação de Mestrado, Programa de Pós-Graduação Interunidades em Ensino de Ciências, Universidade de São Paulo, São Paulo, SP., 2006.

OLIVEIRA, S. S. Concepções alternativas e ensino de biologia: como utilizar estratégias diferenciadas na formação inicial de licenciados. Curitiba: UFPR. Educar, n. 26, p. 233-250, 2005.

PÉREZ, D. Formação de Professores de Ciências: tendências e inovações. $3^{a}$. ed. São Paulo: Cortez, 1998.

POZO, J.I. Teorias cognitivas da aprendizagem. 3a . ed. São Paulo: Artes Medicas, 1998. 